\title{
ESCRITA DE ROTEIROS: A PRODUÇÃO DE UM AUDIOVISUAL NA ESCOLA E A ESCRITA SOBRE SUA APRENDIZAGEM
}

\section{SCRIPT WRITING: THE PRODUCTION OF AN AUDIOVISUAL IN SCHOOL AND THE WRITING ABOUT ITS LEARNING}

\author{
Janaína Aguiar Mendes Galvão* \\ Vera Lucia Bonfim Tiburzio**
}

\begin{abstract}
RESUMO: Este artigo analisa uma proposta de atividade escolar com o objetivo de constitui-la enquanto estratégia para alterar a relação de licenciandos com a escrita, usando gêneros do discurso (BAKHTIN, 2006) que permitem uma compreensão mais simples dos propósitos de produção e parecem mais afins aos interesses espontâneos da juventude. Para embasamento teórico sobre a escrita escolar e universitária, utilizamos uma série de textos (BARBOSA, 2013; GERALDI, 1999 e 2018; COSCARELLI, 1998; DE PIETRI, 2007; LARROSA, 2002; RIBEIRO, 2015) que articulam problemas antigos aos contemporâneos, como o advento das tecnologias de informação e comunicação (TIC), sobre este objeto de estudo. O foco é analisar o processo de escrita de roteiros e a produção de minidocumentários. Posteriormente, contrastar a primeira e a segunda produção audiovisual para destacar mudanças nos parâmetros para representação da escola, da relação professor-aluno, da importância de despertar nos alunos o interesse pelas atividades. Os resultados encontrados demonstram que os textos audiovisuais apresentam informações e reflexões que se apagam no texto escrito, mas podem considerar-se indícios de autoria. Os documentários foram realizados por universitários do curso de Licenciatura em Ciências Biológicas da Universidade Federal do Triângulo Mineiro (UFTM) como atividade do PIBID, numa escola municipal de Uberaba-MG, em parceria com a disciplina de Ciências no Ensino Fundamental II.
\end{abstract}

Palavras-chave: Escrita; Roteiro; Documentário.

ABSTRACT: This article discusses an school activity proposal with the goal of establishing it as a strategy to alter undergraduates' relation with writing, using speech genres (BAKHTIN, 2006) that allow an simpler understanding of production purposes and seem to be more suitable for youths' spontaneous interests. As theoretical background about college and school's writing, we used a series of texts (Barbosa, 2013;

* Doutoranda no Programa de Pós-Graduação em Educação (PPGE) da Universidade Federal do Triângulo Mineiro (UFTM). Docente do Curso de Letras da UFTM. Contato: janaina.galvao@uftm.edu.br

** Professora associada da Universidade Federal do Triângulo Mineiro (UFTM). Doutora em Biologia Molecular e Funcional pela mesma instituição. Contato: vera.tiburzio@uftm.edu.br 
Geraldi, 1999 and 2018; Coscarelli, 1998; De Pietri, 2007; Larrosa, 2002; Ribeiro, 2015) that connect older problems to contemporary ones, with the advent of Information and communications technology (ICT) over this research object. The focus is to analyse script writing process and the production of mini documentaries. Subsequently, to constrast the first and second audiovisuals to highlight changes on parameters for school representation, teacher-student relation and the importance to evoke in students interest for the activities. The results found show that, audiovisual texts present information and reflection that adhere to the written text,this can be considered indications of authorship. The documentaries were done by undergraduates of Universidade Federal do Triângulo Mineiro (UFTM) Biological Sciences course as an PIBID activity, in a municipal school in Uberaba-MG, in partnership with the Sciences subject at Ensino Fundamental II.

Keywords: Writing; Script; Documentary.

\section{INTRODUÇÃO}

Neste artigo, discutimos os resultados obtidos em uma atividade realizada com licenciandos participantes do edital 2018 do Programa Institucional de Bolsa de Iniciação à Docência (PIBID) e docentes deste programa e do projeto de "Leitura e escrita no Brasil, Honduras, Angola e Chile: formação na universidade contemporânea e (re)produção de conhecimento" sobre ensino e aprendizagem da escrita na formação acadêmica. A partir desta análise, será possível descrever, com base nas produções de alunos e licenciandos ${ }^{1}$, estratégias usadas por professores para ensinar a leitura e a escrita na universidade. Serão analisados e discutidos dois minidocumentários escolares com o principal objetivo de analisar a relação entre escrita e aprendizagem, pautando-se no reconhecimento dos propósitos dos textos e do reconhecimento dos gêneros neste caso, o roteiro e o documentário, feitos por licenciandos, realizados para a disciplina de Ciências no Ensino Fundamental II. Ao contrastar a primeira e a segunda produção audiovisual, destacamos mudanças nos parâmetros para representação da escola, da relação professor-aluno, da importância de despertar nos alunos o interesse pelas atividades, embora as mudanças sejam mais perceptíveis no texto audiovisual que no texto escrito do roteiro.

\footnotetext{
1 Usamos 'licenciandos' para universitários e 'alunos' para estudantes da escola. Por 'estudantes', nos referimos aos dois segmentos conjuntamente.
} 
Apresentamos o embasamento teórico no tópico "2.A importância da escrita na formação acadêmica" e utilizamos uma série de textos que articulam problemas antigos aos contemporâneos, como o advento das TIC, com uma reflexão sobre a escrita que acontece fora do âmbito educacional e suas consequências sobre este (Barbosa, 2013; Geraldi, 1999 e 2018; Coscarelli, 1998; De Pietri, 2007; Larrosa, 2002; Ribeiro, 2015). No item "3.O documentário, o Pibid, a universidade, a escola e as fake news" justificamos a produção de textos audiovisuais, tanto na escola como na universidade; as rodas de leitura e escrita; destacamos o gênero documentário e especificamos instruções sobre a escrita de roteiros e os passos percorridos até a tarefa final - a produção do minidocumentário escolar. O tópico posterior "4.Análise e discussão" demonstra a distância entre o texto escrito e o texto audiovisual. Parece-nos que, com a possibilidade de expressão com outras semioses, o texto escrito se transformou e já não cumpre a mesma função de antes. Em "5.Considerações finais", fazemos uma síntese deste texto e prospectamos a produção de textos audiovisuais como estratégia para despertar nos estudantes a importância do seu engajamento nas atividades escolares para fazer vídeos que os divirtam, mas que também os eduquem.

\section{A IMPORTÂNCIA DA ESCRITA NA FORMAÇÃO ACADÊMICA}

A aprendizagem da escrita pelos licenciandos, durante o processo de sua formação universitária, expressa tanto o desenvolvimento do estudante no uso da linguagem quanto a evidência do conhecimento adquirido e articulado ao longo de seus estudos. De acordo com alguns autores, no entanto, os licenciandos não costumam considerar a potencialidade da atividade de escrita na sua formação. Barbosa (2013) observa que:

[...] cada vez mais é comum ouvirmos dos professores universitários a queixa de que o aluno não escreve, não tem autonomia para pensar por conta própria e, sobretudo, tem pouco apego ao que faz na universidade. A produção escrita é vista como algo que pode ser feita sem muitas reflexões e cuidados. A reescrita é vista por esse aluno como um castigo dado pelo professor e não como um trabalho constitutivo da escrita (BARBOSA, 2013. p. 453). 
Essa queixa foi antes feita pela escola. Há quase quarenta anos atrás, foi publicada a obra "O texto na sala de aula", de João Wanderlei Geraldi. Neste livro, há uma denúncia sobre uma atividade escolar de escrita desastrosa, um castigo mesmo, que açoitava professores e alunos, que precisavam matá-la para que outra prática de escrita melhor renascesse das cinzas. Nas palavras de Geraldi:

O exercício de redação, na escola, tem sido um martírio não só para os alunos, mas também para os professores. Os temas propostos têm se repetido de ano para ano, e o aluno que for suficientemente vivo perceberá isso. Se quiser, poderá guardar redações feitas na quinta série para novamente entregá-las ao professor da sexta série [...]

Para o professor, por outro lado, vem a decepção de ver textos mal redigidos, aos quais ele havia feito sugestões, corrigido, tratado com carinho. No final o aluno nem relê o texto com as anotações. Muitas vezes o atira ao cesto de lixo assim que o recebe. (GERALDI, 1999[1984], p.51)

Nem todos os alunos jogaram os textos no lixo. Alguns ingressam no ensino superior (IBGE, 2019). Em 2019, mais de três milhões. Esse número pode ser considerado como sendo aqueles que aprenderam a escrever o suficiente para garantir seu acesso ao ensino superior. Mas descobrem que isso ainda não é o suficiente, porque os professores universitários continuam se queixando e apontando a má qualidade da escrita que seus alunos lhes apresentam em seus textos. E a escola se queixa muito antes que os alunos entrem na universidade. $E$ os alunos são os que mais se queixam de escrever na escola e na universidade. Em sua formação escolar, não puderam compreender a importância de escrever e muito menos de reconhecer que sua aprendizagem deriva da escrita. Coscarelli (1998) lamenta porque:

[...] o modo como fomos ensinados a escrever não foi muito adequado. Na escola tínhamos poucos minutos para escrever a respeito de assuntos sobre os quais não queríamos falar ou sobre os quais nada tínhamos para falar, para alguém que só estava interessado em encontrar muitos erros para corrigir. E o esforço que fizemos durante a escrita, os assuntos que nos interessavam e as experiências que realmente gostaríamos de compartilhar com nossos colegas? Ninguém ligava para elas! Os professores geralmente liam nossos textos tão concentrados em encontrar erros de ortografia e sintaxe que acabavam não ligando para a estrutura dos textos e algumas vezes nem para o significado deles. Nós realmente passamos por momentos difíceis na escola [...] (COSCARELLI, 1998, p.27) 
No texto de Coscarelli, há ainda uma observação que durante certo período se deu um hiato sobre o ensino da escrita dentro da própria formação em Letras, que dava mais relevância à produção oral por afirmar uma filiação aos estudos que emergiam de uma ciência linguística que se impunha na divergência com a perspectiva tradicional, na qual o texto escrito era privilegiado. A isso queremos relacionar as reflexões de De Pietri (2007) ao reconhecer uma tensão fundada ao considerar a escrita escolar como objeto de estudo linguístico, que não podia ser compreendida nem pela tradição anterior, e tampouco pela linguística moderna. Nas palavras do autor:

\begin{abstract}
A hipótese com que se trabalha, então, é a de que a constituição da escrita escolar em objeto dos estudos da linguagem tornou-se possível em função dos problemas que a produção textual escrita apresentou para esses estudos em relação a seu objeto primeiro - a língua, construída em oposição à fala -, e em função da polêmica que estabelece uma situação de delimitação recíproca entre a perspectiva moderna e a perspectiva tradicional de abordagem do fenômeno lingüístico. (DE PIETRI, 2007, p.285)
\end{abstract}

Portanto, é preciso assumir que muito tem sido feito a partir das queixas, das universidades e das escolas; dos alunos e dos professores. Há uma tensão epistemológica da área que vem fazendo dessas queixas um motor para avançar em seu fazer científico a fim de compreender a escrita e alterar os modos como, na prática escolar e acadêmica, ela pode vir a ser mais do que hoje é, assim como reconhecemos que já houve transformações entre o que ela era no passado e como se apresenta atualmente, constituindo, dessa forma, um objeto de estudo que sempre vai apresentar desafios para aprimorar e diversificar a compreensão de sua importância na formação escolar e acadêmica.

No entanto, mesmo reconhecendo que as pesquisas sobre escrita estão em constante transformação, o modo como muitos estudantes chegam à universidade é desinteressado da escrita enquanto processo e direcionado ao reconhecimento de uma norma a seguir, vazia de sentido e cheia de formalidades impositivas. Talvez por não terem experimentado, de fato, escrever como um desafio para obter uma recompensa em proveito de sua própria aprendizagem, o que ninguém pode lhe dar, é ele mesmo, enquanto autor, quem 
experimenta. Esta experiência de aprendizagem, ou seja, o saber da experiência é conceituado por Jorge Larrosa (2002) como "isso que me passa", a cada sujeito que enuncia "eu" em sua particularidade. Ainda sabendo que sua origem está fora de mim e me depara, consequentemente, com a alteridade, é reconhecido como subjetivo (me diz algo importante de mim mesmo), reflexivo (só eu compreendo o que ele é), transformador (me projeta em um movimento que dá significado ao que me era desconhecido).

Se a experiência não é o que acontece, mas o que nos acontece, duas pessoas, ainda que enfrentem o mesmo acontecimento, não fazem a mesma experiência. O acontecimento é comum, mas a experiência é para cada qual sua, singular e de alguma maneira impossível de ser repetida. $O$ saber da experiência é um saber que não pode separar-se do indivíduo concreto em quem encarna. Não está, como o conhecimento científico, fora de nós, mas somente tem sentido no modo como configura uma personalidade, um caráter, uma sensibilidade ou, em definitivo, uma forma humana singular de estar no mundo, que é por sua vez uma ética (um modo de conduzir-se) e uma estética (um estilo). Por isso, também o saber da experiência não pode beneficiar-se de qualquer alforria, quer dizer, ninguém pode aprender da experiência de outro, a menos que essa experiência seja de algum modo revivida e tornada própria (LARROSA, 2002, p.27).

É a escrita que demonstra a experiência de aprendizagem que o licenciando expressa sobre sua área de formação. Às vezes, muitas ou poucas, os estudantes são aprovados sem experimentar aprender ao escrever, porque atendem aos requisitos formais de uma escrita pautada no 'template' da norma que respeitam, sem que deem significado aos propósitos que a norma contempla. Porém, prescindem de experimentar a escrita como um saber de experiência, intransferível, reflexivo e transformador. Acreditam que escrever não é um saber que se afirma enquanto próprio, mas que é a(o) professora, o seu outro, quem o aprova ou reprova, sem assumir uma responsabilidade para com aquilo que escrevem. Preocupam-se pela forma do que escrevem, não pelo significado do que escrevem. Sem saber exatamente o que escrever, justificam suas produções em como a escreveram 'corretamente'. Não legitimam critérios que os corrijam ou questionem para além daqueles que não se pautem na norma que forjam atender.

Por outro lado, é preciso que entendam que a escrita na universidade exige esta apreciação mais complexa da finalidade dos textos que the são 
demandados, e, mais do que isso, que devem estabelecer uma relação fundamental entre o escrever e o aprender, o saber, o conhecer, para resultar em pesquisa e conhecimento. É vital que a universidade aceite esse desafio de fazer com que seus estudantes compreendam os propósitos de produção dos textos pelos quais a universidade engendra conhecimento. Mas antes desta compreensão, talvez a universidade deva, em primeiro lugar, intrometer-se na relação que os discentes estabelecem com a escrita, seja na universidade, ou antes, na escola, ou na compreensão de como sempre escreveram em sua atividade escolar. Para tal, é preciso que o ato de escrever se instaure a partir de uma finalidade que o concretize, uma ação que tenha mais sentido de dentro para fora do que de fora para dentro. Coscarelli (1998) adverte que:

\begin{abstract}
A única maneira de resolver esse problema é sabendo como a escrita funciona. Nós, professores, precisamos saber pelo menos que existem condições em que a escrita normalmente acontece. Só se escreve quando existe um propósito para isso, quando há um recebedor (mesmo que seja o próprio autor), e quando há o que escrever (informação nova). Precisamos também saber que escrever envolve a geração, seleção e organização de ideias. Isso significa que escrever requer a produção de um rascunho que deve ser revisto e reescrito mais de uma vez (COSCARELLI, 1998, p.28).
\end{abstract}

Alunos da escola básica e licenciandos são demandados, 'normalmente', a escrever em suas atividades escolares e acadêmicas, gostem ou não (os professores ou os estudantes) das normas de escrita que se consideram (ou não) dentro de um parâmetro da normalidade institucional. Entre os textos escolares e universitários, ao concluir a escola básica, os alunos prestam o Exame Nacional do Ensino Médio (ENEM) e a redação é o que 'normalmente' mais atormenta aos avaliados. Entretanto, para além da normalidade da escrita escolar e universitária, alunos e licenciandos escrevem 'normalmente', quer dizer, escrevem espontaneamente, sem ninguém pedir/mandar? Em que condições a escrita acontece, 'normalmente', no contexto da atualidade dessa nova geração da escola e da universidade?

Para alterar a relação dos estudantes com a escrita, é fundamental intrometer-se em conscientizar os universitários de que eles estão rodeados de "artefactos letrados" (CASSANY, 2008), que leem e escrevem o tempo todo ao 
realizar suas atividades mais cotidianas e privadas (para pegar um ônibus, agendar compromissos, pedir comida, separar o lixo, fazer compras, inscreverse num concurso, dar likes, conversar com os amigos por redes sociais, selecionar uma boa série pra assistir, participar de uma live, escolher que passeio farão quando a pandemia acabar) ou seja, toda a vida que vivem, na rua ou em casa, dentro ou fora dos muros da escola e da universidade.

\begin{abstract}
A vida é dialógica por natureza. Viver significa participar do diálogo: interrogar, ouvir, responder, concordar, etc. Nesse diálogo o homem participa inteiro e com toda a vida: com os olhos, os lábios, as mãos, a alma, o espírito, todo o corpo, os atos. Aplica-se totalmente na palavra, e essa palavra entra no tecido dialógico da vida humana, no simpósio universal (BAKHTIN, 2006 [1979], p. 348).
\end{abstract}

Geraldi (2018) diz que nunca se escreveu tanto diante das "inúmeras possibilidades tecnológicas disponíveis" (GERALDI, 2018, p.1). A escrita persistiu (no fax, no chat, no blog, no email e mesmo nas redes sociais como Facebook, Twitter, Whatsapp) apesar do avanço e da novidade dos novos posts em imagem e vídeo. O autor adverte que há diferenças "nesse mar de escritas" (GERALDI, 2018, p.1) dos textos produzidos 'normalmente' em nossa sociedade atual e critica a miudeza das mensagens, consideradas longas se não se enquadram em poucas linhas nas quais não cabe nenhuma reflexão: "[...] Mas posts/mensagens em textos curtos não são mais do que uma "manchete" quando trazem link para outros espaços - ou meras opiniões sem que o autor se sinta na obrigação de justificá-las" (GERALDI, 2018, p.2). Da mesma forma, recrimina a pressa pela qual assistir a dez minutos de vídeo seja um limite, porque vê-los até o fim parece insuportável ou desnecessário: "[...] quando a duração ultrapassa 15 minutos, se tornam excessivos [...] a "presença" do ouvinte é inferior ao tempo da fala, [...] comentários que mostram uma escuta que não chegou ao fim" (GERALDI, 2018, p.2). Geraldi alerta a respeito de um papel das TIC que exigem uma transformação da função social desempenhada pela escola: 
[...] se a escola deixa de ser o lugar da socialização do conhecimento, sua função agora há de ser outra. Parece-me que ela é a única instituição social capaz de cumprir outro papel, aquele da reflexão.

Se vivemos correndo, sendo bombardeados por informações, já não precisamos mais delas. Aquilo de que precisamos é refletir sobre elas, estabelecer conexões, buscar uma reflexão conjunta que permita sabermos afinal o que estamos vivendo.

Para contemplar de outro modo a atividade de escrita que acontece 'normalmente', Ribeiro (2015) defende que o uso de recursos tecnológicos para produzir textos contribui para realçar relações de sentido com outras semioses, para além do texto verbal. Desse modo, no texto "Tecnologia e poder semiótico: escrever, hoje", a autora resume suas reflexões:

Em uma paisagem comunicacional em que é possível empregar muitos recursos tecnológicos e obter diversos efeitos, em muitas modulações de linguagem, é importante pensar a produção de textos em níveis de multimodalidade cada vez mais expressivos. A escola pode participar desse cenário, ao propor a reflexão e a prática sobre a escrita, contribuindo para a ampliação do "poder semiótico" das pessoas, a despeito da ênfase que vem sendo dada à "redação do ENEM", no ensino médio. (RIBEIRO, 2015. p.112)

Sem escamotear o aspecto histórico que caracteriza a escrita, dependente em grande parte de condições tecnológicas, a autora ressalta que, assim como criamos novas máquinas, criamos também novos gêneros textuais juntamente a novos modos de escrever. Ler e escrever se constituem como práticas que dizem respeito a nossa maneira de viver em sociedade. Ribeiro (2015) reconhece um poder que as tecnologias digitais possibilitaram ao ato de produzir textos.

Em nossa história presente, as tecnologias digitais apontam para a intensificação dos usos de diferentes modos semióticos, isto é, é esperado que se use uma "multiplicidade de modos, e em particular a imagem - parada ou em movimento - assim como outros modos, como a música e os efeitos sonoros, por exemplo" (KRESS, 2003, p.5). E não porque esses modos não existissem antes, é claro, mas porque houvesse restrições de ordem técnica ou especializada para seu manejo, algo que as tecnologias digitais (e seus editores de tudo, na forma de softwares intuitivos), definitivamente, amenizaram. (RIBEIRO, 2015. p.117). 
Ao tomar os modos como Geraldi (2018) e Ribeiro (2015) se referem à escrita a partir das TIC, revela-se um conflito que pretendemos articular. $O$ primeiro ressalta que as TIC só se legitimam enquanto conteúdo de ensino se a escola puder substituir 'informação' por 'reflexão', adentrar profundamente nos temas de estudo, por meio de infinitos "links" que permitem uma compreensão reflexiva sobre conhecer, ler e escrever, ultrapassando generalidades e superficialidades. O segundo destaca uma potencialidade das TIC para intensificar os usos de modos semióticos diversos para uma produção de textos que explorem níveis de multimodalidade cada vez mais expressivos. Consideramos que a análise da expressividade dessas interações espontâneas pode permitir a reflexão necessária para levá-los a significar os propósitos dos textos que produzem por vontade própria, bem como daqueles que thes são demandados.

As oportunidades de escrita com gêneros não acadêmicos podem estabelecer um modo novo de pensar a escrita como experiência, para além do "template" da forma e em direção a aspectos importantes da produção de textos - o que tenho a dizer? Para quem? Com qual objetivo? Em que circunstância? Em que condições será "lido" (visto ou ouvido também)? - Vale insistir com Larrosa (2002, p.27) que será preciso entender a escrita não como algo que está fora (o conhecimento científico, por exemplo), mas "somente tem sentido no modo como configura uma personalidade, um caráter, uma sensibilidade ou, em definitivo, uma forma humana singular de estar no mundo."

Para desenvolver o ensino e a aprendizagem da escrita acadêmica e compreender como superar as dificuldades que caracterizam este processo (admitido como um problema contemporâneo e globalizado) é inevitável problematizar a relação que os universitários experimentam 'normalmente' com sua escrita espontânea de maneira a torná-los capazes de desenvolver reflexões mais robustas de leitura e gestos mais expressivos de autoria. Alterar esta relação com a escrita passa também por criar iniciativas didáticas que descrevam estratégias para o ensino da escrita e da leitura na universidade², por

2 Conforme um dos objetivos específicos do projeto de pesquisa "Práticas de leitura e escrita de alunos do Brasil, Angola, Chile e Colômbia: produção de conhecimento e formação no ensino 
meio de gêneros que sejam mais palatáveis para os licenciandos e os permitam estreitar laços objetivos e subjetivos com a atividade de escrita.

A atividade escolar, objeto de análise deste artigo, incide sobre alterar a relação da aprendizagem com a escrita para os licenciandos, que tiveram uma experiência de escrever roteiros para produzir minidocumentários (o que permite explorar diferentes níveis de multimodalidade entre o texto escrito do roteiro e o texto multimodal do minidocumentário audiovisual), criados para a disciplina de Ciências, no Ensino Fundamental II ${ }^{3}$.

\section{O DOCUMENTÁRIO, O PIBID, A UNIVERSIDADE, A ESCOLA E AS FAKE NEWS}

Um grupo de 6 licenciandos dos períodos iniciais do curso de Licenciatura em Ciências Biológicas da UFTM trabalhou semanalmente, por três semestres, na E. M. Prof. José G. Guimarães de Uberaba-MG, realizando rodas de leitura e escrita e oficinas sobre Ciências e Tecnologia (C\&T) com alunos de diferentes anos do Ensino Fundamental II, no período do contraturno. Dessas rodas, surgiu a proposta de solicitar aos licenciandos escreverem roteiros para produzir minidocumentários sobre C\&T, como atividade do PIBID.

Um dos objetivos pretendidos pelo PIBID, conforme o edital (CAPES, 2018), é a inserção dos alunos de licenciatura na rotina de escolas públicas, "proporcionando-Ihes oportunidades de criação e participação em experiências metodológicas, tecnológicas e práticas docentes de caráter inovador e interdisciplinar [...]" (p.3).

Estabelecer uma rotina de atividades realizadas no contraturno é um desafio que precisar entregar alguma novidade aos alunos da escola básica, para que eles queiram participar além da carga horária já cumprida em seu período regular de estudos. Nesse sentido, propor uma produção audiovisual, como atividade escolar, incorpora interesses mais afins às atividades de leitura

superior": e) descrever, a partir das produções de alunos, as estratégias usadas por professores para ensinar a leitura e a escrita na universidade.

3 Ainda que possamos reconhecer uma forte tendência interdisciplinar da atividade, todas as atividades (planejamento, elaboração e execução) foram realizadas exclusivamente por bolsistas do PIBID de Ciências Biológicas (coordenação, supervisão e iniciação à docência). 
e escrita realizadas fora da escola pelos alunos. No que diz respeito aos licenciandos, o desafio é trazer o fora da escola para dentro dos processos de ensino e aprendizagem e construir conhecimento com dotes do entretenimento e lazer mais habituais dos alunos. Os adolescentes despendem muito de seu tempo livre consumindo e produzindo audiovisuais que circulam (nas redes sociais, nos celulares e até em programas de TV) sem nenhuma preocupação sobre o conhecimento que veiculam. Produzir um audiovisual que também ofereça aprendizagem sobre o conteúdo escolar é importante na medida em que o propósito deixa de ser só 'aparecer' e se expor na rede, mas passa a exigir uma reflexão sobre o conteúdo do que se vai apresentar. Esta responsabilidade ficou a cargo dos licenciandos que, como professores em formação inicial, assumiram a elaboração dos roteiros e organizaram a produção do audiovisual na escola.

De acordo com Melo (2021):

O documentário está fortemente associado ao campo do jornalismo, isso porque ambos, jornalismo e documentarismo, são tomados como discursos que buscam oferecer acesso ao real, à verdade. No entanto, tal objetivo é inalcançável, pois a representação do mundo é sempre determinada por um ponto de vista, nunca é a coisa em si mesma. Se no início de sua história o documentário buscou representar a realidade de forma objetiva e imparcial, aos poucos ele foi se distanciando desse fim, [...] muitos são os documentários que questionam essa possibilidade. (MELO, 2021, p.14).

Entre a proposta do documentário e sua realização houve muitas tarefas envolvidas. A dinâmica de trabalho dos licenciandos intercalava reuniões de planejamento (com as professoras orientadoras) e rodas de leitura e de escrita e oficinas (com os alunos da escola). Para as rodas de leitura, os licenciandos selecionavam um tema de interesse, atendendo também aos assuntos tratados nas aulas de Ciências. Durante sua realização, os licenciandos distribuíam textos de revistas de divulgação científica e/ou fragmentos de livros acadêmicos para leitura com os alunos. As discussões sobre os textos os colocavam em diálogo com fake news selecionadas, cuja circulação se prolifera por meio de redes sociais às quais os alunos pertencem e frequentam, uma vez que já estão integradas à interação social experimentada amplamente em nossa sociedade. Este elo entre a leitura e as fake news cumpriu um objetivo fundamental ao 
enfatizar a leitura interativa, afirmando que 0 ato de ler envolve tanto 0 conhecimento prévio do leitor quanto a informação do texto (KLEIMAN, 2006). Mostrar ao aluno que sua formação escolar pode melhorar sua relação com as novas tecnologias e conscientizá-lo da importância da atividade reflexiva de sua leitura, que se vale dos conhecimentos aprendidos e discutidos na escola para diferenciar informações que circulam simultaneamente em fluxo na rede e poder legitimá-las ou não, refutá-las ou não, compartilhá-las ou não. Como objetivo escolar, não relevamos somente a especificidade do aprendizado em Ciências, mas principalmente a missão mais importante, atualmente, que consiste em orientar os alunos a usarem um conhecimento construído na escola para diferenciar informações verdadeiras de falsas e se posicionarem criticamente sobre elas. As rodas de escrita e oficinas permitiram cumprir as tarefas de captação de imagens - registros originais, material de arquivo e recursos gráficos (PUCCINI, 2009), além da confecção de figurinos e cenários para os minidocumentários.

Para a elaboração dos roteiros, os licenciandos receberam duas indicações de leitura da coordenação: Hampe (1997) e Puccini (2009). Nos dois casos, tratam-se de textos voltados para a produção cinematográfica, com detalhamento de procedimentos técnicos, discussões sobre produção e orçamento e aspectos conceituais desta área que fogem ao escopo deste trabalho e que não interessam para uma articulação com o documentário como uma atividade escolar. Entretanto, vamos tomar algumas orientações mais pontuais com relação a propósitos cumpridos pelo roteiro de documentário ${ }^{4}$.

Segundo Hampe (1997, p.6), um roteirista contribui para a produção de um documentário cinematográfico por meio da pesquisa e planejamento, da visualização, da organização da estrutura do documentário e da redação do texto:

O roteiro abrange todas as etapas do documentário: início, meio e fim. É escrito em cenas que descrevem todas as ações e falas que devem ocorrer em determinados locais e em determinados momentos. Começa-se uma

4 Seria muito favorável desenvolver a atividade em parceria com a disciplina de língua portuguesa. Há um maior rigor com a contextualização dos temas de ciências do que com os processos de escrita. Por exemplo, seria importante que os alunos vissem documentários e lesses roteiros antes de passarem para a etapa de produção. 
nova cena toda vez que se muda o tempo ou o espaço da ação. Um roteiro normalmente inclui diálogos de atores. Mas nas cenas de vida real, ou em depoimentos, o roteiro apenas menciona o que se espera que as pessoas possam dizer. $(1997$, p.6)

Puccini (2009) descreve diferentes etapas para o roteiro, conforme avançam os estágios da produção cinematográfica. Selecionamos sua definição para 'argumento', por entender que está afim à descrição de roteiro feita por Hampe (1997) e pela possibilidade de problematizá-la durante a análise dos roteiros escritos em relação aos minidocumentários:

[...] trata-se de um resumo da história com início, desenvolvimento e resolução. No argumento ficam estabelecidos personagens principais, ação dramática, tempo e lugar dessa ação e os eventos principais que irão compor essa história. [...] Mesmo nos casos de documentaristas que preferem explorar as relações nascidas do embate com o real (como no caso dos filmes do Documentário Direto), todo filme é resultado de uma ação planejada. (PUCCINI, 2009. p.184).

Vamos analisar dois minidocumentários cujos roteiros foram redigidos de forma coletiva pelos licenciandos, sob orientação das professoras orientadoras: 1) "Existe vida na escola aos sábados?", sobre conhecimentos de astronomia e 2) "Feirinha Pacaembu", sobre a feitura de uma horta na escola.

\section{ANÁLISE E DISCUSSÃO}

Os licenciandos reescreveram os roteiros a partir das intervenções docentes (questionamentos, acréscimos, perguntas, instruções) realizadas pela coordenadora diretamente aos textos escritos. A reescrita "é um trabalho constitutivo da escrita" (BARBOSA, 2013. p. 453), mas é conhecido e difamado como "castigo" pelos estudantes, que costumam realiza-lo com mais resistência do que empenho. Ao considerar satisfatório o processo de refaç̧ão dos roteiros produzidos (para cada roteiro foram 3 versões), os licenciandos passavam à produção dos minidocumentários audiovisuais, processo no qual parece não ter havido intervenções docentes. Ou porque, se houve alguma intervenção, esta falhou ao problematizar/corrigir/alterar alguns parâmetros que se referem à 
representação da escola, de material didático, da relação professor-aluno, da importância de considerar o papel dos alunos e seu interesse pela atividade, principalmente ao analisar o primeiro minidocumentário apresentado.

Do nosso ponto de vista, esta postura não revela que as professoras preteriram a produção audiovisual e priorizaram o roteiro escrito, mas sim que, embora a linguagem audiovisual goze de muito prestígio com alunos e licenciandos fora da escola, dentro dela e para as professoras é o texto escrito que lhes compete. Talvez porque as professoras não se sentiram seguras para intervir nas produções audiovisuais, ou por considerar que diante destas são os estudantes os protagonistas. Dessa forma, o roteiro escrito foi revisto e refeito até alcançar sua versão final, mas o audiovisual mereceria também intervenções e reflexões na versão final apresentada, conforme apontaremos em seguida, com foco no primeiro minidocumentário.

Ao receber o primeiro roteiro do minidocumentário "Existe vida na escola aos sábados?" sobre o conteúdo de astronomia, há um questionamento da coordenadora posto diretamente ao título, por meio do seguinte comentário: "Não entendi o título. Por que aos sábados? [...] Qual a relação do título com o conteúdo de Astronomia?'. A resposta a este comentário é apresentada na segunda versão do roteiro:

O documentário pretende acompanhar um dia de sábado dos alunos na
Escola [...]. Será realizado um teatro em que alguns alunos da escola e
os licenciandos serão caracterizados de personagens que remetem ao
tema astronomia. Os alunos participantes das oficinas do Pibid
representarão extraterrestres de um planeta fora do Sistema Solar e
farão questionamentos para os licenciandos. Os questionamentos serão
relacionados aos assuntos trabalhados nas oficinas durante o semestre,
tais como: Quem são vocês? De onde vocês vieram? (Relacionam-se às
oficinas que explicam o surgimento do planeta Terra, o surgimento da
vida no planeta). Os licenciandos do subprojeto de Ciências Biológicas
interpretarão astronautas do planeta Terra, visitantes no planeta dos
extraterrestres [...] alguns licenciandos farão parte do teatro, outros
surgirão no documentário explicando os questionamentos de uma
maneira científica. (Roteiro sobre o tema Astronomia)

O vídeo do documentário, de fato, contempla a descrição feita acima. No entanto, apresenta vários elementos que não estão materializados no roteiro, embora se possa notar que foram planejados para o texto audiovisual. Por 
exemplo, ao iniciar o vídeo, apresenta-se uma cena ${ }^{5}$ de lançamento de uma nave espacial com a inscrição na tela "Live from kennedy space center" (ao vivo do centro espacial Kennedy) acompanhada de uma narração em inglês. Não há nenhuma informação que referencie data e local do lançamento apresentado "ao vivo", o que demonstra que esta cena não tem valor documental, mas sim ilustrativo. Quando a contagem regressiva é concluída, a nave decola e apresenta-se uma vinheta de abertura do documentário com uma animação de um foguete no espaço e os nomes das professoras orientadoras e dos licenciandos que assinam o minidocumentário, imagens e textos apresentados simultaneamente a uma trilha sonora.

$\mathrm{Na}$ sequência à abertura, uma tomada ${ }^{6}$ mostra o letreiro da escola $\mathrm{e}$ depois uma licencianda caracterizada como astronauta (pelo capacete) que caminha (movendo-se com a dificuldade típica de astronautas quando estão na lua) até o portão da escola. Esta cena também é acompanhada de uma trilha sonora de suspense, cujo ápice é o portão da escola se abrindo. Do lado de dentro, há extraterrestres (os alunos maquiados e portando diversos acessórios) surpresos com a visitante que chega. Um deles pergunta: "Quem são vocês? De onde vocês vieram?". Então a visitante se apresenta: "Eu sou um astronauta e vim do planeta Terra que se encontra no sistema solar". A licencianda/O astronauta dá informações sobre o planeta (o terceiro mais próximo do sol, rochoso, no qual a atmosfera permite a manutenção da temperatura e dos gases, o único no qual há presença de água na forma líquida) que se apresentam ilustradas em animações sobrepostas à filmagem. Ao final da fala do astronauta, o minidocumentário encadeia, em cortes diretos $^{7}$, perguntas dos alunos extraterrestres e explicações de um(a) licenciando(a) que aparece em cena,

5 Cena - É uma ação que ocorre num mesmo espaço e recorte temporal, [...] por mesmo espaço, estamos nos referindo ao ambiente estrito no qual a(s) personagem(ns) se encontra(m). (MELO, 2021, p.62).

6 Tomada - filmagem contínua gravada sem cortes que começa no momento em que se liga a câmera até o momento em que ela é desligada. (MELO, 2021, p.196).

7 Corte - passagem de um plano a outro. Todo corte pressupõe a existência de dois planos: 0 que vem antes do corte (por convenção, chamado de "Plano A") e o que vem depois do corte ("Plano B"). Do ponto de vista do espectador, o corte é a sensação de mudança de ponto de vista. Tipos de corte: Corte Direto - (também chamado de Corte Seco ou Corte Simples, ou ainda Corte Propriamente Dito) - ocorre quando a passagem de um plano a outro se dá sem qualquer estado intermediário. (MELO, 2021, p.188). 
individualmente, vestindo um jaleco branco na frente de um quadro negro onde está escrito "EU TE EXPLICO". São três perguntas feitas pelos alunos extraterrestres: 1) "Qual o planeta mais quente do sistema solar?", 2) "Estrelas cadentes são estrelas?", 3) "Como vocês fazem para saber se há vida fora da Terra?". As explicações são características de uma aula expositiva tradicional, com a diferença de que simultaneamente ao texto oral das respostas dadas pelos licenciandos, são projetadas animações ou imagens sobrepostas que ilustram as explicações fornecidas, típicas do documentário expositivo:

No modo expositivo de representação da realidade, o documentarista aspira passar a impressão de objetividade [...] o documentarista investe em estratégias de enunciação que causam efeito de distanciamento, neutralidade, indiferença e onisciência, as quais correspondem à maneira como a voz que narra surge na tela: [...] encarnada numa "figura de autoridade" que se faz ver e ouvir em cena. [...] Esses recursos são muito utilizados em documentários de cunho científico e didático dotados de forte função moral, social e pedagógica. (MELO, 2021, p.27).

Respondidas as três perguntas, retoma-se a mesma vinheta para 0 encerramento, com os mesmos créditos, concluídos com a inscrição do intertítulo8 "Muito obrigada" no fim.

Queremos tomar as imagens e cenas do audiovisual para refletir sobre a distância entre o texto do roteiro e o documentário, que são dois textos diferentes entre si, embora estejam relacionados. O audiovisual é "escrito" com imagens, sons, intertítulos e diálogos que evidenciam traços de autoria do audiovisual, evidenciando um "poder semiótico" (Ribeiro, 2015) que se acrescenta ao texto escrito. O roteiro, segundo as fontes que a docente Ihes forneceu, deveria ser "[...] um resumo da história com início, desenvolvimento e resolução. [...] personagens principais, ação dramática, tempo e lugar dessa ação e os eventos principais que irão compor essa história" (PUCCINI, 2009. p.184). No entanto, o texto escrito escamoteia esses traços e silencia questionamentos que nos parecem pertinentes para aprimorar o documentário em si e colocá-lo em

8 [...] intertítulos, ou cartelas de informação textual inscritas na tela, as animações (figurativas ou não), a inserção e ilustração de dados técnicos (números, escalas, gráficos) e [...] fotografias e documentos relevantes. (MELO, 2021, p.53). 
contraste com o que se escreveu no roteiro: 1) Se somente há uma pessoa que chega caracterizada como astronauta, por que a pergunta do aluno extraterrestre é feita no plural? São alienígenas que sempre veem no plural? Esta característica poderia ter sido representada por efeitos de imagem. Por não terem empregado este efeito, a pergunta não deveria ter sido reformulada, no singular? 2) Por que a licencianda se apresenta como UM astronauta e não UMA astronauta? A profissão astronauta não tem gênero? Não há mulheres astronautas no planeta Terra? E no Brasil, há mulheres astronautas? Ou pode ser que a licencianda esteja reverberando o discurso oficial, muito característico do material didático como masculino, neutro, geral, mas que, em nossa opinião, deveria ter sido problematizado para relacioná-lo ao intertítulo final: "Muito obrigada". 3) Por que, ao escrever o roteiro, o texto audiovisual não é "escrito" de fato, mas tratado tão somente como apresentação mais geral do conteúdo temático do audiovisual? Por que o audiovisual não é para "ler" e sim para "ver"? 4) Por que os alunos são caracterizados como extraterrestres se, ao receberem a resposta à terceira pergunta "Como vocês fazem para saber se há vida fora da Terra?" são informados de que extraterrestres não existem, fato comprovado cientificamente por muitas pesquisas voltadas à investigação sobre o tema. Não parece muito coerente com o título "Existe vida na escola aos sábados?" que os personagens representados pelos alunos sejam mera ficção, portanto excluídos do discurso científico e da disciplina de Ciências na escola. 5) Os diálogos do audiovisual não são interações orais espontâneas entre alunos e licenciandos o que justificaria que não estivessem materializados no texto do roteiro - mas, são, entretanto, textos escritos oralizados, representativos da linguagem padrão e do discurso científico, mas que não estão escritos, de fato, no roteiro. 6) Nos créditos do minidocumentário, aparecem os nomes das professoras orientadoras e dos licenciandos mas, com relação aos alunos que participam do documentário, há somente "Extraterrestres: alunos da E.M. José Geraldo Guimarães". Os alunos, além de serem extraterrestres (que não existem) também não têm nome? 7) A vida que existe na escola aos sábados não diz respeito à vida dos alunos que concretamente existem e que têm um nome que os singulariza. 8) As fake news trabalhadas nas rodas de leitura, tão importantes 
para contextualizar a proposta de produção dos minidocumentários, foram descartadas.

O segundo minidocumentário desenvolve uma relação muito mais sincera com do roteiro, o que nos permite considerar que os licenciandos puderam compreender melhor a finalidade do gênero escrito que estavam produzindo, alterando sua relação com a escrita. Porém, queremos analisar antes o texto audiovisual. O minidocumentário inicia-se com uma vinheta de abertura na qual se escuta a música "A feira" (Rappa, 1996): "É dia de feira [...] / quem quiser pode chegar", se apresentam os créditos com os nomes das professoras orientadoras e dos licenciandos autores e se veem fotos de uma feira local e seus diversos postos de vendas de frutas, legumes, hortaliças, além da movimentação das pessoas que circulam na feira. Em seguida, inicia-se uma tomada ambientada numa sala de aula, onde se lê no quadro negro "Feira do Pibid" e aparecem um licenciando e uma aluna anunciando as hortaliças produzidas na horta da escola e colhidas recentemente, expostas sobre uma mesa. Logo após, alunos consumidores vão entrando em cena e fazendo perguntas sobre como podem consumir as hortaliças. As respostas dadas incluem dicas de preparo, diferentes pratos e formas de consumo, além da descrição de benefícios nutricionais dos produtos apresentados. Há uma alternância entre aluna e licenciando - protagonistas produtores da feira do Pibid - ao fornecer as informações, ora dão dicas mais práticas de consumo nos pratos típicos, ora explicitam os benefícios nutricionais dos alimentos oferecidos. $\mathrm{O}$ plano ${ }^{9}$ seguinte retoma o modo expositivo do documentário. Ao fim da cena da feira do Pibid, são apresentadas imagens de alimentos in natura e cenas de pessoas comendo em restaurantes, simultâneas a uma narração em voz over ${ }^{10}$ sobre hábitos de alimentação dos brasileiros, baseados numa pesquisa realizada pelo IBGE em 2015, apresentando intertítulos como

9 Plano - É um trecho contínuo de filme entre dois cortes consecutivos. No momento da gravação, corte corresponde à interrupção da filmagem. Já com o filme pronto, o corte equivale à passagem de um plano a outro. (MELO, 2021, p.62).

10 Voz Over (ou narração em over) - indicação usada quando não vemos e não sabemos quem está falando. Trata-se da chamada "voz de Deus", narrador onipresente e onisciente que conta a história sem manter vínculo com ela. Ele narra de forma distanciada. $O$ efeito que obtém com isso é o de objetividade. (MELO, 2021, p.198). 
gráficos, tabelas, ilustrações dos dados da pesquisa e de orientações para equilibrar as refeições. Em suma, as informações da narração em conjunto com as imagens estáticas ou em movimento advertem sobre um excesso de consumo de alimentos ultraprocessados, sobretudo entre os jovens, e problemas de saúde associados a estes maus hábitos de alimentação. Na próxima tomada do minidocumentário, são exibidas fotos e cenas dos alunos trabalhando na horta com os licenciandos, mexendo na terra, plantando, rindo, conversando e existindo na escola. Não é possível escutar seus diálogos porque o áudio é uma música instrumental. Na vinheta de encerramento, são apresentados os nomes de todos que aparecem no documentário e as funções que representam (feirantes e clientes), nomeando os alunos personagens do documentário, diferentemente do procedimento com o primeiro documentário. O que se mantem são os textos escritos oralizados - o que parece apontar que fazer um audiovisual na escola não é compatível com uma fala espontânea e/ou descuidada, afirmando, pois, uma expressão linguística na qual se reconhece que a língua padrão é um objetivo da formação escolar, que, curiosamente, não está registrada no texto escrito do roteiro (como 'normalmente' seria o esperado).

Ao contemplar o segundo minidocumentário, ressaltamos algumas mudanças significativas no processo da atividade de ensino e aprendizagem, tanto do roteiro quanto do documentário, uma vez que os parâmetros já mencionados (representação da escola, de material didático, da relação professor-aluno, da importância de considerar o papel dos alunos e seu interesse pela atividade) se apresentam de maneira muito díspar em relação ao primeiro minidocumentário e se materializam, de fato, no texto audiovisual (neste, de forma muito mais expressiva do que no roteiro). 1) No segundo minidocumentário audiovisual, os alunos não aparecem como figurantes em cortes que diferenciam os planos entre licenciandos e alunos, como descrito no primeiro, mas sim coexistem numa tomada em cenas sucessivas que registram sua participação por perguntas contextualizadas à situação de frequentadores de uma feira. 2) Diferentemente do quadro "EU TE EXPLICO" do documentário anteriormente analisado, tanto a aluna quanto o licenciando se colocam em diálogo e alternam os turnos para se apropriarem do discurso cientifico a respeito dos nutrientes 
encontrados nos produtos da horta e da importância da inclusão de alimentos in natura nas refeições diárias. 3) Além disso, reagem ao fato de que esta feira entrega muito mais que produtos, mas principalmente informações que os permitem ler, isto é, compreender, interpretar, consumir os produtos de outra maneira, pelo fato de identificarem seus nutrientes e os efeitos conseguintes - 0 conhecimento científico sobre os produtos divulgados - em relação à saúde e aos hábitos necessários para conquista-la, o que representa melhor qualidade de vida social.

Não obstante, afirmamos que essas alterações relevantes respondem diretamente às intervenções docentes postas ao texto escrito do roteiro - a reescrita, castigo de aluno e sermão da professora. A primeira versão deste roteiro descrevia o tópico "Procedimento geral" em duas sucintíssimas linhas: " $O$ documentário se embasará em técnicas manuais de cultivo de horta escolar, cultivo orgânico de espécies de hortaliças, ervas, temperos." Talvez estivessem com preguiça de escrever, como 'normalmente' acontece. A coordenadora, por outro lado, aprendeu com a experiência do primeiro audiovisual - toma esta produção como um rascunho e vai apontando os caminhos da sua própria reescrita - e sabe que precisa especificar o que espera da relação deste roteiro com o audiovisual que será produzido:

\begin{abstract}
Enviem as falas que serão apresentadas no documentário para que eu possa corrigir. Não apareceu aqui quais serão os dados provenientes de pesquisas que vocês usarão no documentário. Gráficos, tabelas etc, mostrando informações vindas do levantamento bibliográfico que vocês fizeram (ou farão) sobre o tema. É um documentário e não somente um vídeo com encenação de vocês. Sugestão: procurem por dados nacionais (ou regionais) sobre consumo de orgânicos, por exemplo (Texto da intervenção docente).
\end{abstract}

Nesta intervenção, a coordenadora não faz simplesmente um comentário. Ela dá instruções de uma forma bastante objetiva sobre qual é sua expectativa em relação ao roteiro, com orientações em imperativo, enumeração de tarefas, definição de documentário e, por fim, uma sugestão sobre alimentos orgânicos (veja-se que a sugestão está no final, todo o resto é ordem mesmo - inclusive quando diz o que não é pra fazer: "não é somente um vídeo com encenação de 
vocês"). Dessa forma, indica como realizar a tarefa do documentário, que se fará a partir de um texto de roteiro, para que o resultado seja melhor do que a experiência anterior e que ela possa intervir no texto, oportunidade que o primeiro documentário não lhe deu.

Na segunda versão deste roteiro, após a intervenção docente, o procedimento geral virou outra coisa:

\begin{abstract}
Procedimento geral: $O$ documentário se embasará em técnicas manuais de cultivo de horta escolar, cultivo orgânico de espécies de hortaliças, ervas, temperos. Serão apresentados dados relacionados a importância do consumo de alimentos naturais, e comparações de informações nutricionais de alimentos naturais e industrializados (aqueles mais consumidos diariamente por adolescentes). Será demonstrado maneiras diferentes de consumir hortaliças e ervas, de modo que os alunos possam ter curiosidade de experimentá-los e saborear. Durante as encenações serão realizados alguns questionamentos dos alunos, tais como: Para que serve o alface na nossa alimentação? Como se utiliza um tempero? Que outra hortaliça posso usar em salada? A beterraba é saudável? As respostas serão apresentadas com informações científicas demonstrando informações nutricionais, forma de cultivo da planta etc. (Roteiro sobre o tema Horta)
\end{abstract}

Posto isto, as alterações apontadas entre a realização do primeiro e do segundo minidocumentário não se encontram explicitamente nos textos escritos dos dois roteiros, que mantêm como característica a generalidade das informações sobre a temática tratada. Os roteiros reiteram a expectativa sobre a escrita que "pode ser feita sem muitas reflexões e cuidados" (BARBOSA, 2013. p. 453). Entre os dois audiovisuais, podemos assinalar mudanças sobre os parâmetros anteriormente destacados, mas estes são, de fato, evidenciados nos minidocumentários, nos quais se deixam notar de forma mais expressiva, revelando um "poder semiótico" (RIBEIRO, 2015) que agrega informações - a propósito, agrega reflexões (GERALDI, 2018, p.2) - que foram omitidas nos roteiros escritos. Embora os licenciandos tenham sido instruídos sobre a função de planejamento a ser cumprida por este gênero, os textos mantêm as mesmas características, apontando apenas de forma geral como os temas foram trazidos nas produções audiovisuais. Impõe-se o questionamento: como convencer esses estudantes de que o texto escrito do roteiro permite materializar seus gestos de autoria e criatividade que se apresentam 'normalmente' manifestos no texto multimodal do minidocumentário audiovisual? 


\section{CONSIDERAÇÕES FINAIS}

As primeiras intervenções, feitas ao texto escrito, nos permitem afirmar que este gênero era pouco conhecido pelos licenciandos, considerando a produção inicial que foi apresentada. As dificuldades iniciais na escrita dos roteiros (falta de clareza, coerência ou estruturação lógica, uso de argumentação pautada apenas em senso comum ou em opiniões próprias, sem embasamento sólido, além do uso inadequado de termos técnicos próprios da C\&T) foram se modificando a partir das intervenções realizadas a cada uma das três versões entregues de cada um dos roteiros.

Dessa forma, os documentários ganharam elementos (gráficos, tabelas, animações, narrações) que nos permitem caracterizá-los como minidocumentários de atividades escolares, sobre 0 conhecimento proporcionado pela disciplina de Ciências, embora no texto escrito apareçam por meio de descrições gerais com apontamentos superficiais para o tratamento dos temas.

De uma maneira geral, é importante perceber como o desconhecimento do gênero documentário vai se descortinando na realização da produção audiovisual. É a ação de compreender o gênero que se altera no texto escrito, ainda que somente de maneira parcial, mas se concretiza no minidocumentário. Ao produzir o primeiro roteiro, a coordenadora questiona que o texto não descreve os ambientes e as ações realizadas, e que, portanto, o texto não cumpre sua função enquanto roteiro. Na segunda versão do texto, os roteiros contextualizam melhor as ações retratadas e indicam diálogos determinando perguntas e possíveis respostas sobre o tema que será o conteúdo das cenas apresentadas. Como comentário ao roteiro do segundo minidocumentário, a coordenadora acrescenta um questionamento ao observar que, se somente há cenas entre licenciandos e alunos sendo mostradas pelo vídeo, ainda não é um documentário, que eles precisam inserir os conhecimentos que as rodas de leitura geraram, inclusive porque foi desse processo anterior que o tema foi definido para o documentário. 
Ao assistir aos minidocumentários, percebe-se que os roteiros escritos continuam descrevendo, apenas parcialmente, os resultados dos textos audiovisuais, ainda apresentando lacunas. No entanto, os vídeos não mostram somente licenciandos e alunos em interação. Principalmente, o resultado exige que licenciandos e alunos se coloquem em interação com o conhecimento da disciplina, o que não parecia importante para os atores que participaram no processo. Para os alunos, aparecer no vídeo, isto é, participar de um audiovisual feito na escola já pareceu motivo suficiente para sua adesão. Para os licenciandos, registrar a interação estabelecida com os alunos - apresentar imagens e sons do interesse dos alunos e sua participação voluntária nas atividades - foi considerado suficiente para cumprimento da proposta do projeto, uma vez que as cenas colhidas para o documentário pareciam mais relevantes que a escrita de um texto que sistematizasse como o vídeo apresentaria os dados colhidos em imagens e som.

Se estabelecermos uma relação entre o conteúdo do roteiro e do documentário há uma série de omissões, como a de falas dos personagens por exemplo. Parece-nos pertinente indagar sobre onde escreveram os textos "dos diálogos" representativos da linguagem padrão e do discurso científico, apresentados no documentário, mas que não constam no roteiro. Em que outro texto, que não o roteiro, foi escrito o que "dizem" alunos e licenciandos nos vídeos, ao notar que não são falas espontâneas, mas sim textos escritos oralizados?

O objetivo desta análise não é apresentar esta atividade como ela foi, vai além, queremos apontar o que ela poderia ser, e ainda poderá, no futuro. 1) A produção audiovisual é um atrativo para os alunos da escola mas é preciso garantir que sua realização esteja pautada na aprendizagem de conteúdos escolares, nas concepções de fala e escrita, na convivência em grupo, no trabalho em equipe, no respeito à escola e a todos que trabalham nesse espaço, no sentimento de pertença à comunidade onde a escola existe. 2) Vários professores, várias disciplinas podem (aliás, devem) colaborar para uma produção audiovisual feita na escola. Suas etapas de planejamento, escrita e realização podem ser propostas em horário contraturno, como projetos 
complementares aos estudos regulares. Os alunos comparecem e trabalham. Se alguns acham que só porque fizeram um vídeo quiseram fazer a horta, maior se apresenta o argumento em favor da produção do audiovisual. 3) Os licenciandos já podem sair do castigo da reescrita para interagir com seus próprios textos e entrarem em diálogo com o que 'escreveram' no audiovisual e deletaram nos roteiros escritos. A atividade de reescrita do roteiro, após a conclusão do minidocumentário, Ihes daria a oportunidade da experiência da aprendizagem que deriva da escrita e que "envolve a geração, seleção e organização de ideias" (COSCARELLI, 1998, p.28) por meio das quais imprimem "poder semiótico" (RIBEIRO, 2015) ao texto audiovisual, mas que escamoteiam no texto escrito. Seria um ensejo para fazê-los reconhecer que os aspectos fundamentais de sua atividade discursiva - seja no roteiro escrito ou no texto audiovisual - têm no cerne as relações dialógicas entre os textos, entre os atores da escola, entre a escola e comunidade, etc. A análise dessas interações em textos multimodais pode permitir a reflexão necessária para levá-los a significar os propósitos dos textos que produzem por vontade própria, bem como daqueles que Ihes são demandados com vistas ao aprofundamento de seus conhecimentos escolares e acadêmicos e das relações que os materializam. 4) Se os adolescentes, que despendem tanto de seu tempo assistindo vídeos (no Youtube, nas redes, na TV, no Whatssap) que não têm nenhum conteúdo, quem sabe não podem passar a considerar a importância do seu engajamento nas atividades escolares para fazer vídeos que os divirtam, mas que também os eduquem.

\section{REFERÊNCIAS}

BARBOSA, M. V. A difícil arte de ensinar o aluno de graduação apor assinatura nas suas produções. Revista do GELNE, Natal, v. 15, p. 451-469. 2013.

BAKHTIN, Mikhail M. Estética da Criação Verbal. [tradução feita a partir do russo; tradução Paulo Bezerra]. 5. ed. São Paulo: Martins Fontes, 2006 [1979].

BONDIA, Jorge Larrosa. Notas sobre a experiência e o saber de experiência. Tradução de João Wanderley Geraldi. Revista Brasileira de Educação, n. 19, 2002. 
BRASIL. Programa Institucional de Iniciação à Docência - PIBID. Edital no 7/2018, de 1ำ de março de 2018: chamada pública para apresentação de propostas. Disponível em: <https://uab.capes.gov.br/educacaobasica/capespibid/editais-e-selecoes >. Acesso em: 27 abr. 2021.

BRASIL. INSTITUTO NACIONAL DE ESTUDOS E PESQUISAS EDUCACIONAIS ANÍSIO TEIXEIRA. Censo da Educação Superior: Notas Estatísticas $\quad-\quad 2019.2$ Disponível em: $<$ https://download.inep.gov.br/educacao superior/censo superior/documentos/ 2020/Notas Estatisticas Censo da Educacao Superior 2019.pdf>. Acesso em: 27 abr. 2021.

CASSANY. D. Prácticas letradas contemporáneas. México: Ríos de Tinta, 2008. Disponível em: <https://www.upf.edu/web/daniel cassany/practicasletradas-contemporaneas >. Acesso em: 31 jul. 21.

COSCARELLI, C. V. Os alunos aprendem o que os professores ensinam? In: GONÇALVES, Gláucia; RAVETTI, Graciela (Orgs.). Lugares Críticos. Belo Horizonte: Orobó,UFMG, 1998.

COUTO, H. H. O. M. e REZENDE, L. A. Documentário de divulgação científica. Ensino, Saúde e Ambiente, v. 5, n. 2, p. 160-172, 2012.

DE PIETRI, E. A constituição da escrita escolar em objeto de análise dos estudos lingüísticos. Trab. Ling. Aplic., Campinas, v. 46, p. 283-297, Jul./Dez. 2007

GERALDI, João Wanderley. et al. (orgs.). 0 texto na sala de aula. 3. ed. São Paulo: Ática, 1999.

GERALDI, J.W. A escola e as tecnologias. V. 2, n. 9 (2018): ANAIS do UEADSL2018.2. Disponível em:

$<$ http://www.periodicos.letras.ufmg.br/index.php/ueads//article/view/14474>

Acesso em 27. mai. 2021.

HAMPE, B. Making documentary films and reality videos. New York: Henry Holt and Company, 1997. (Tradução: Roberto Braga).

KLEIMAN, A. Leitura e prática social no desenvolvimento de competências no ensino médio. In: BUNZEN, C.; MENDONÇA, M. (orgs.). Português no ensino médio e formação do Professor. São Paulo: Parábola, 2006.

MELO, C. T. V. et al. Caderno do Professor: Olhar em movimento: cenas de tantos lugares. Disponível em:

www.escrevendoofuturo.org.br/caderno virtual/caderno/documentario. $2^{\mathrm{a}} \mathrm{ed}$; 2021. Acesso em: 30 set. 2021. 
PUCCINI, Sergio. Introdução ao roteiro de documentário. Doc On-line: Revista Digital de Cinema Documentário, São Paulo, v. 13, 2009.

RIBEIRO, A. E. Tecnologia e poder semiótico: escrever, hoje. Texto Livre, Belo Horizonte, v. 8, n. 1, p. 112-123, 2015. 